\title{
Social organization and caste formation in three additional parasitic flatworm species
}

\author{
Osamu Miura* \\ Oceanography Section, Science Research Center, Kochi University, 200 Monobe, Nankoku, Kochi, 783-8502 Japan
}

\begin{abstract}
There are many examples of reproductive division of labor in terrestrial animal societies, but only a few have been reported in aquatic systems. A recent study discovered social organization of a trematode parasite in a marine system which included reproductive and soldier castes. Here I expand that work, reporting on caste formation in 3 species of trematodes infecting the Asian mud snail Batillaria attramentaria, to demonstrate the generality of this phenomenon. I found that the trematodes Philophthalmid sp. I, Philophthalmid sp. II and Acanthoparyphium sp. I have 2 types of morphologically and functionally distinct larval trematode morphs in their colonies. Large morphs were reproductive and filled with embryos, while small morphs had no embryos. Small soldier morphs were disproportionately common in regions within the host where new infections occur, and had relatively large mouthparts. Finally, only small soldier morphs attacked heterospecifics. Division of labor in trematodes is geographically widespread and has now been documented in North America, East Asia and Oceania; this may provide a useful model for comparing ecology and evolution of social organization in animal societies.
\end{abstract}

KEY WORDS: Trematode - Sociality · Caste - Batillaria attramentaria - Philophthalmidae · Acanthoparyphium

\section{INTRODUCTION}

Societies with castes are common in terrestrial systems, particularly among insects. Hymenopteran insects such as ants (Wilson 1971), wasps (Matthews 1968, Klahn \& Gamboa 1983) and bees (Batra 1964, Michener 1969) show substantial division of labor. Termites (Myles 1999), aphids (Aoki 1977, Rhoden \& Foster 2002) and thrips (Crespi 1992) have also developed unique social systems with caste formation. Social insects are widely distributed and abundant in terrestrial systems (e.g. May 1989). Social organization is a very successful lifestyle in terrestrial systems (Wilson \& Kinne 1990, Chapman \& Bourke 2001). In contrast, sociality involving separate castes of mobile organisms seems to be rare in aquatic systems. Only Caribbean snapping shrimps (Duffy 1996) and a North American sea anemone (Ayre 1982, Ayre \&
Grosberg 1996, Ayre \& Grosberg 2005) have been reported to exhibit a reproductive division of labor.

Hechinger et al. (2011) demonstrated that a parasitic flatworm, Himasthla sp. B, exhibits social organization involving a reproductive caste and a nonreproductive soldier caste. Himasthla sp. B is a trematode that forms colonies in the California horn snail Cerithideopsis californica (Hechinger et al. 2011). Trematodes infect snails as their first intermediate host and asexually produce clone mates (rediae or sporocysts) (Galaktionov \& Dobrovolskij 2003). Hundreds of redia clone mates can comprise a colony in a snail. Rediae produce cercaria larvae that leave the colony and disperse to continue the life cycle. Typically, all generations are diploid, and those resulting from infection with one miracidia larva are genetically identical (Cable 1971). Hechinger et al. (2011) showed that about half of the 
rediae in Himasthla sp. B colonies do not produce cercariae and are specialized for attacking and killing conspecific or heterospecific competitors. Thus, for the first time, they documented a reproductive division of labor in a parasitic flatworm involving a non-reproductive soldier caste. Reproductive rediae produce numerous offspring, and are large and inactive. Soldier rediae do not produce offspring, are small but have relatively large mouthparts, are more active, are aggressive towards noncolony conspecifics and heterospecifics, and are disproportionally common at sites within the host where new infections occur.

Trematodes are common in freshwater and marine ecosystems. Diverse guilds of trematodes infect a variety of marine and freshwater snails (Yamaguti 1975). Although individual trematodes are small, their colonies can comprise $>40 \%$ the weight of an infected snail (Hechinger et al. 2009) and their total biomass within an ecosystem can exceed that of top predators in some estuaries (Kuris et al. 2008). Considering the high diversity and biomass of these parasites, it is possible that social organization is also a pervasive and successful lifestyle in aquatic systems. Further, as with social insects, trematodes may provide a rich system to test hypotheses about the ecology and evolution of sociality. Hechinger et al. (2011) predicted the widespread occurrence of trematode castes, and I demonstrate this in 3 more species. In the present study, I investigate morphological and behavioral features of 3 trematodes infecting an Asian mud snail to evaluate the existence of caste formation. I focus on quantifying basic morphological differences (body and mouthpart size), attack rates toward heterospecifics and conspecifics, caste numbers in colonies, and morph distribution in snails.

\section{MATERIALS AND METHODS}

\section{Sample collection}

The mud snail Batillaria attramentaria was collected at Mangoku Bay in Miyagi prefecture Japan $\left(38^{\circ} 25^{\prime} 59.5^{\prime \prime} \mathrm{N}, 141^{\circ} 24^{\prime} 46.2^{\prime \prime} \mathrm{E}\right)$ between August 2011 to April 2012. Adult snails ( $3 \mathrm{~cm}$ shell length) were dissected under a stereomicroscope. The trematode colonies were sampled in blind fashion from the snails. Trematode species were identified using morphological characters following Hechinger (2007). Observations suggested that 3 species of trematodes (Philophthalmid sp. I, Philophthalmid sp. II and
Acanthoparyphium sp. I) possess soldier and reproductive castes. These species were used for subsequent morphological and behavioral examination. The larval stages of these parasites are described (Hechinger 2007), but do not have species binomials associated as the adult worms in the final host have not been described. Although Philophthalmid sp. II are known to have 3 genetically distinct cryptic species (Miura et al. 2005), they were not distinguished in the present study.

\section{Morphological analyses}

Under a stereomicroscope, larval trematodes (rediae) were separated from the dissected host. I used random grid numbers to collect 50 to 100 individuals (ind.) from each colony. I fixed the rediae with $10 \%$ hot formalin. Digital pictures of each morph were taken using a compound microscope with an Olympus DP 70 camera system at 20 to $40 \times$ magnification for body total length and maximum width and 100x for pharynx length and width. For the 3 trematode species, I measured the body and pharynx size of 46 to 118 ind. for several colonies: 9 colonies for Philophthalimid sp. I, 8 for Philophthalmid sp. II and 6 for Acanthoparyphium sp. I, for a total of 1677 rediae. All measurements were obtained using image analysis software WinRoof Ver. 5.02 (Mitani Corporation). I calculated body and pharynx volumes of redia using the approximation of a cylinder. I recognized 2 redia morphs with clear morphological disparity (Figs. $1 \& 2$ ). I postulated that these are the soldier and reproductive morphs shown in Hechinger et al. (2011). I used general linear mixed models to compare redia body sizes in different castes. Colonies were treated as a random effect. I have deposited the voucher specimens at the Tohoku University Museum (TUMC Nos. 111184 to 111198).

\section{Attack rates}

To evaluate aggression of each redia morph against its self, conspecific and heterospecific colonies, I performed 4 treatments for each colony; 30 ind. of the soldier morph and $20 \mathrm{ind}$. of the reproductive morph were collected from a colony, and 10 ind. of the reproductive morph were collected from different colonies (as conspecific enemies). I also collected 20 ind. of rediae (reproductive morph) from a different trematode species, Cercaria batillariae (as hetero- 

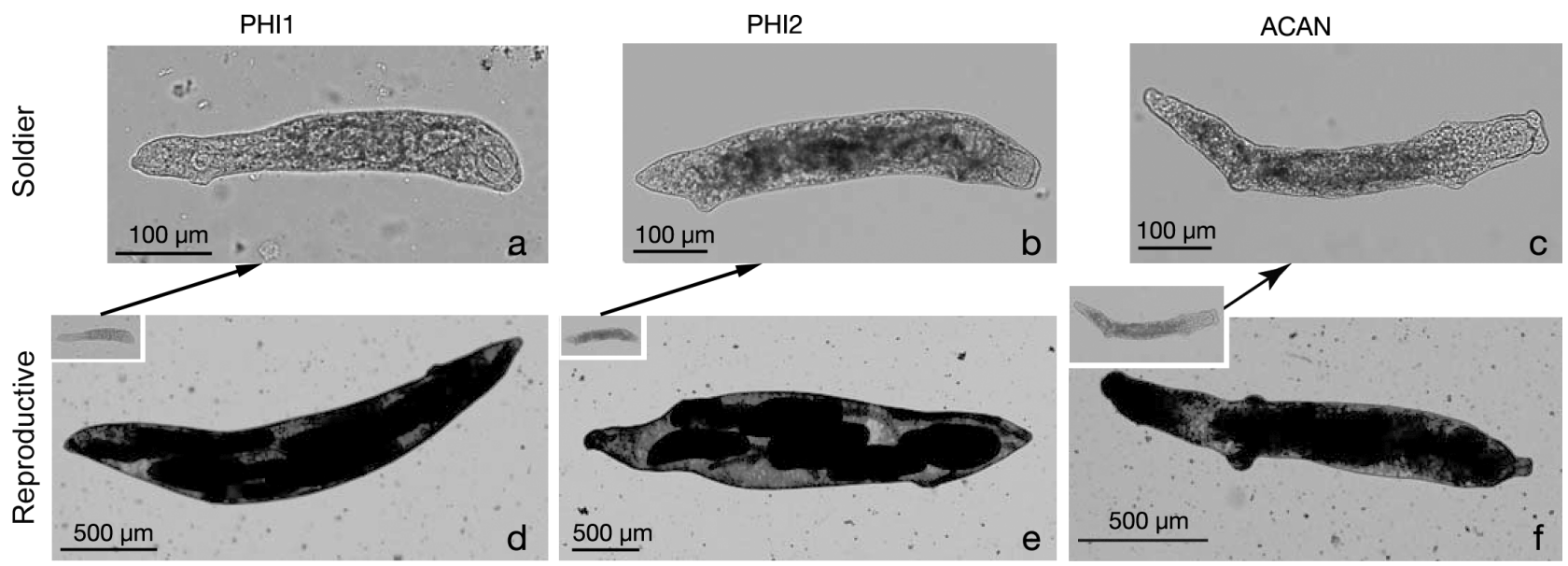

Fig. 1. Reproductive and soldier rediae of (a,d) Philophthalmid sp. I (PHI1), (b,e) Philophthalmid sp. II (PHI2) and (c,f) Acanthoparyphium sp. I (ACAN). Soldier rediae $(\mathrm{a}, \mathrm{b}, \mathrm{c})$ in insets of $(\mathrm{d}, \mathrm{e}, \mathrm{f})$ at the same scale as reproductive rediae
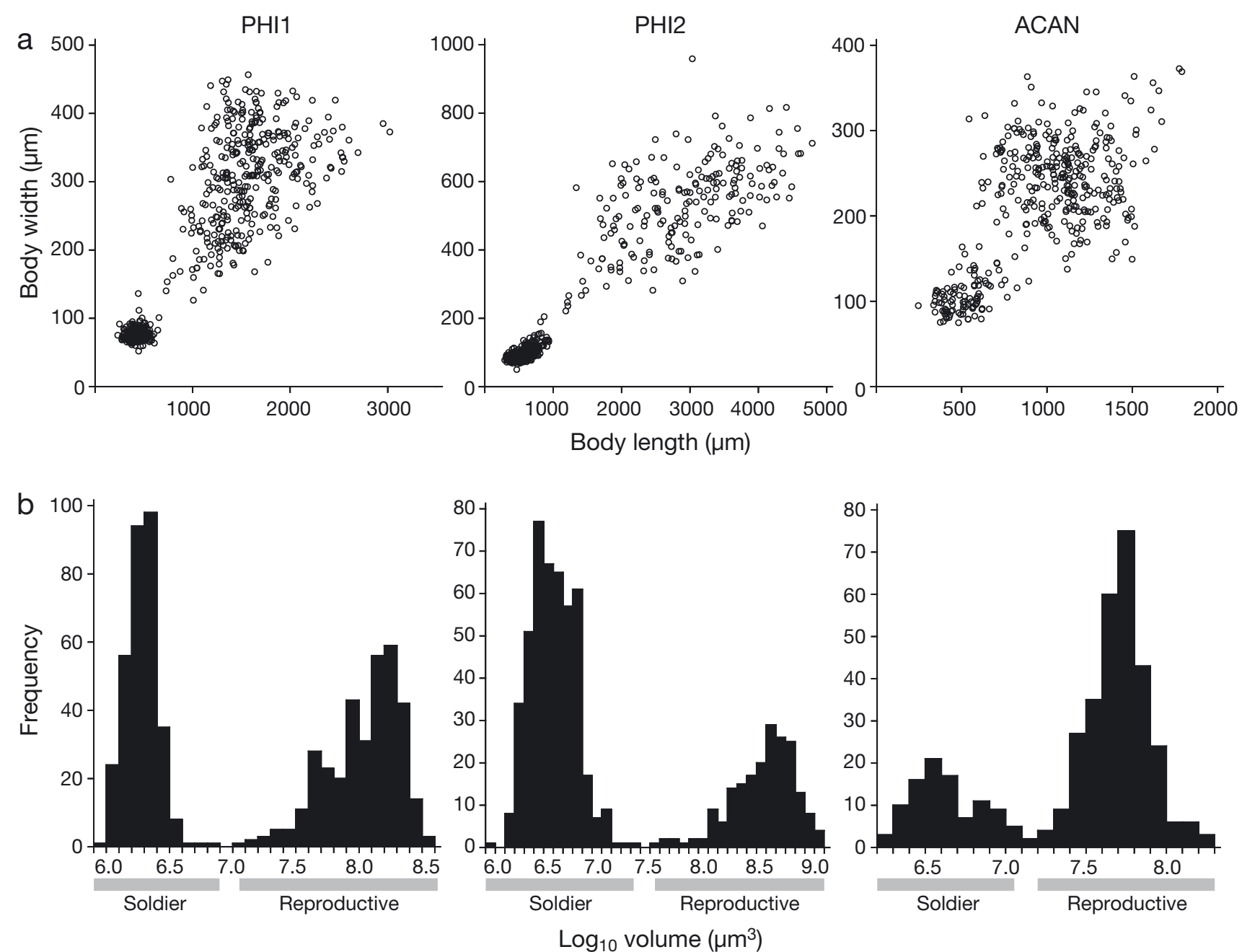

Fig. 2. (a) Body length and width of the rediae and (b) distribution of redia size. Philophthalmid sp. I (PHI1), Philophthalmid sp. II (PHI2) and Acanthoparuphium sp. I (ACAN). Horizontal grey bars indicate the range of the 2 caste groups 
specific enemies). Experiments consisted of different rediae being placed together in a $0.3 \mathrm{ml}$ plastic well with $0.1 \mathrm{ml}$ of RPMI-1640 medium. There were 4 treatments: (1) 10 soldiers and 10 reproductives from the same colony, (2) 10 soldiers and 10 C. batillariae heterospecifics, (3) 10 soldiers and 10 reproductives from different colonies and (4) 10 reproductives and 10 C. batillariae heterospecifics. The experiments were conducted during daytime at room temperature $\left(20\right.$ to $25^{\circ} \mathrm{C}$ ). I counted the number of rediae attacking other rediae $\sim 2 \mathrm{~h}$ after setting the experiments. I repeated the experiment 30 times using different colonies (10 colonies for Philophthalmid sp. I, 10 for Philophthalmid sp. II, and 10 for Acanthoparyphium sp. I). I compared the attack rates of (1) soldiers on reproductives from the same colony and on heterospecifics and of (2) soldiers on reproductives from same colony and on conspecifics using paired $t$-tests for each trematode species.

\section{Distribution within host}

Free-living larvae of trematodes (miracidia) often infect snails by penetrating the exposed part of the snail's head and mantle (Galaktionov \& Dobrovolskij 2003). Soldiers may assemble in the invasion front to defend their colony against new infections. To test this, I compared the distribution of reproductives and soldiers within 24 individual snails. I dissected the snails and split each body into mantle, middle and gonad, following Hechinger et al. (2011). Snail tissues from each region were dissected in glass dishes with saline, and different redia morphs were counted. Snail tissues were squashed between 2 glass slides, and rediae within the tissues were counted using a compound microscope at 20 to $40 \times$ magnification. I counted total redia morphs for Philophthalmid sp. I (10 colonies), Philophthalmid sp. II (9), Acanthoparyphium sp. I (5). I evaluated the distribution patterns of trematodes among 3 snail body regions, controlling for the effect of specific colonies, using the CochranMantel-Haenszel test.

\section{Statistical platform}

All analyses were performed using JMP V. 9.0 (SAS Institute). I ensured approximate normality of the residuals and homogeneity of variance by inspecting normal quantile plots with Lilliefors confidence limits.

\section{RESULTS}

\section{Morphology}

Each of the 3 trematode species exhibited 2 distinct redia morphs (Fig. 1). Reproductive rediae were always filled with several early to late-stage embryos, while none of the 150 soldier rediae (50 ind. for each species) that I inspected under high magnification had free embryos. Reproductives were larger than soldiers (Fig. 2) and never overlapped in body volume (Figs. $2 b$ \& 3). The average volume of reproductives was 65 times larger than that of soldiers for Philophthalmid sp. I $\left(F_{1,650.5}=1112.0, \mathrm{p}<0.001\right), 160$ times larger than that for Philophthalmid sp. II $\left(F_{1,642.0}\right.$ $=1172.7, \mathrm{p}<0.001)$ and 11.5 times larger than that for Acanthoparyphium sp. I $\left(F_{1,364.3}=414.9, \mathrm{p}<0.001\right.$, see Fig. 3). In absolute dimensions, reproductives had 2.1 to 2.6 times larger mouthparts (muscular pharynxes) than did soldiers (Fig. 4a) (for Philophthalmid sp. I, $F_{1,651.1}=983.1, \mathrm{p}<0.001$; for Philophthalmid sp. II, $F_{1,639.7}=947.0, \mathrm{p}<0.001$; for Acanthoparyphium sp. I, $\left.F_{1,364.4}=93.0, \mathrm{p}<0.001\right)$. However, soldiers had much larger mouthparts relative to their body size than did reproductives (Fig. 4b): 18 times larger for Philophthalmid sp. I $\left(F_{1,650.0}=3428.7\right.$, $\mathrm{p}<0.001), 45$ times larger for Philophthalmid sp. II $\left(F_{1,639.8}=1727.7, \mathrm{p}<0.001\right)$ and 5 times larger for Acanthoparyphium sp. I $\left(F_{1,364.8}=913.0, \mathrm{p}<0.001\right)$.

\section{Attack rates}

Soldiers attacked heterospecific rediae of Cercaria batillariae, while they did not attack reproductives from the same colony for Philophthalmid $\mathrm{sp}$. I $\left(t_{9}=\right.$

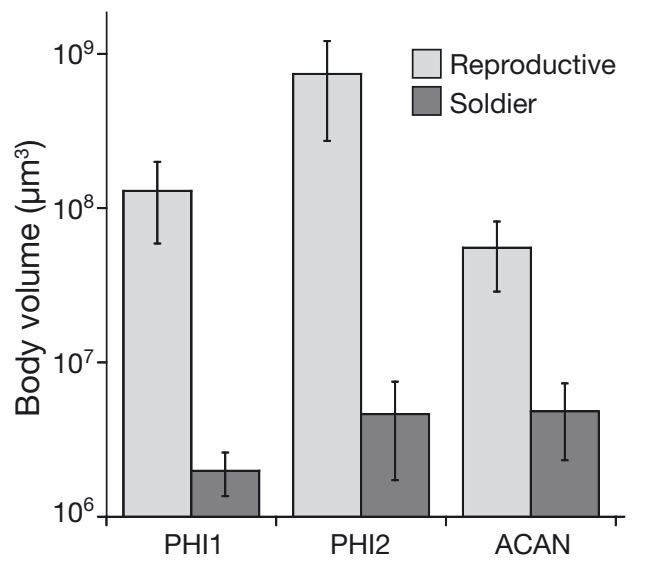

Fig. 3. Body volume of reproductive and soldier rediae. Philophthalmid sp. I (PHI1), Philophthalmid sp. II (PHI2) and Acanthoparyphium sp. I (ACAN). Means \pm SD 

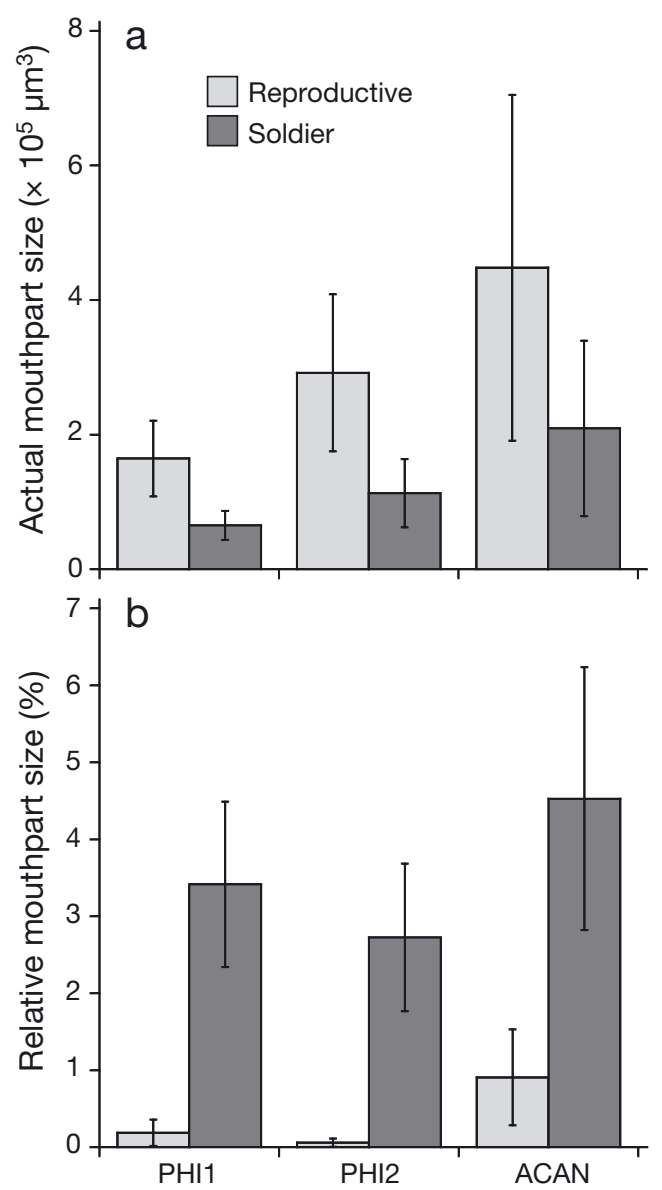

Fig. 4. (a) Actual mouthpart volume and (b) relative mouthpart volume of reproductive and soldier rediae. Philophthalmid sp. I (PHI1), Philophthalmid sp. II (PHI2) and Acanthoparyphium sp. I (ACAN). Means \pm SD
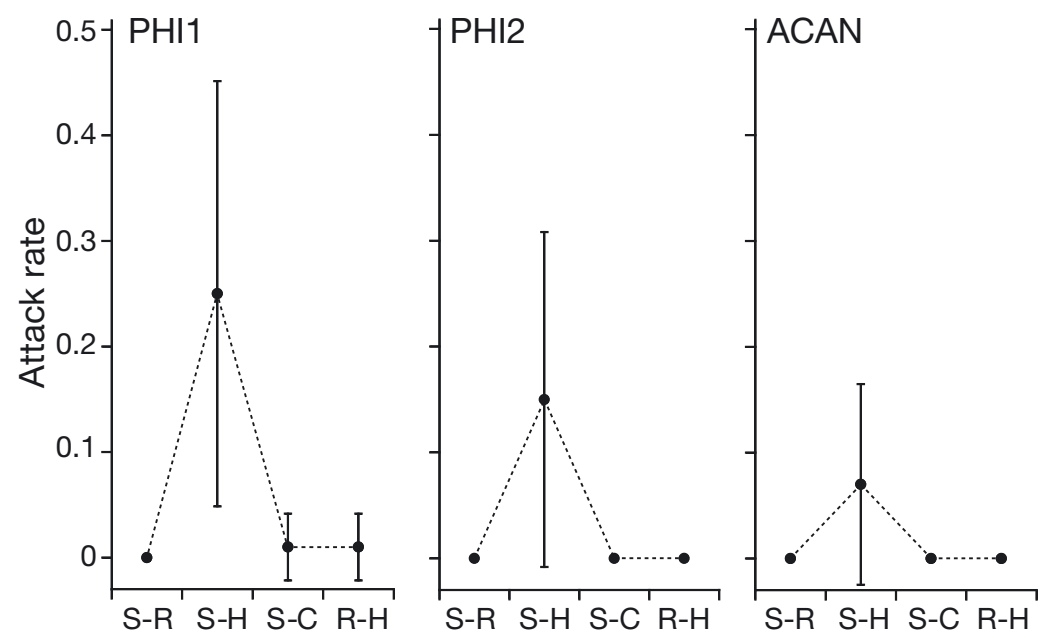

Fig. 5. Attack rates of soldiers on reproductive rediae from same colony (S-R), on heterospecifics (S-H) and on conspecific non-colony mates (S-C). Attack rates of reproductive rediae to heterospecifics $(\mathrm{R}-\mathrm{H})$ is also shown. Philophthalmid sp. I (PHI1), Philophthalmid sp. II (PHI2) and Acanthoparyphium sp. I

$(\mathrm{ACAN})$. Means $\pm \mathrm{SD}$
3.92, $\mathrm{p}=0.004)$, Philophthalmid sp. II $\left(t_{9}=3.59, \mathrm{p}=\right.$ $0.004)$ or Acanthoparyphium sp. I $\left(t_{9}=2.33, \mathrm{p}=0.045\right.$; Fig. 5). Neither soldiers of Philophthalmid sp. II nor of Acanthoparyphium sp. I did attack conspecific noncolony mates (Fig. 5). Philophthalmid sp. I soldiers attacked conspecific non-colony mates, but this occurred only once ( $t_{9}=1, \mathrm{p}=0.343$; Fig. 5). Reproductives were inactive in the experimental wells, while soldiers actively moved and twisted their bodies. When soldiers encountered heterospecific rediae, they briefly contacted the body surface of heterospecifics with their mouths. After repetitive contact, soldiers attached to heterospecifics with their mouths, and by contracting an expanding their muscular pharynxes they slowly consumed heterospecifics. Attacks lasted from a few minutes to several hours. Soldiers also contacted the rediae of colony mates with their mouths, but never attacked. Reproductives rarely actively contacted other rediae and rarely showed aggressive behavior (Fig. 5).

\section{Caste numbers and distribution within the host}

Total and relative numbers (caste ratios) of each redia morph in colonies varied among the 3 trematode species (Fig. 6a,b). Total numbers of soldiers and reproductives was greatest in Philophthalmid sp. I $\left(F_{2,21}=5.83, \mathrm{p}=0.009\right)$. Caste ratios for this species were $\sim 1: 1$, as there was no statistical difference on the mean number of reproductives and soldiers in a single colony $\left(F_{1,47}=0.03, \mathrm{p}=0.87\right)$. However, Philophthalmid sp. II, on average, had 3 times more soldiers than reproductives $\left(F_{1,42}=19.3, \mathrm{p}<0.001\right)$. Acanthoparyphium sp. I had $\sim 5$ times as many reproductives as soldiers in a single colony $\left(F_{1,22}=7.2, \mathrm{p}=0.014\right)$.

Redia morphs of all 3 species were unevenly distributed within the host tissues (Fig. 7) ( $\mathrm{df}=2, \mathrm{n}=11,408, \chi^{2}=$ 2309.9, $\mathrm{p}<0.001$ for Philophthalmid sp. I; df $=2, \mathrm{n}=6020, \chi^{2}=247.2, \mathrm{p}<$ 0.001 for Philophthalmid sp. II; $\mathrm{df}=2$, $\mathrm{n}=2913, \chi^{2}=1059.8, \mathrm{p}<0.001$ for Acanthoparyphium sp. I). Most rediae occurred in the gonadal region (Fig. 7a). However, soldiers were much more abundant than reproductives in the mid-region and mantle, and comprised almost $100 \%$ of rediae in the mantle furthest from the bulk of the infection in the gonad (Fig. 7b). 

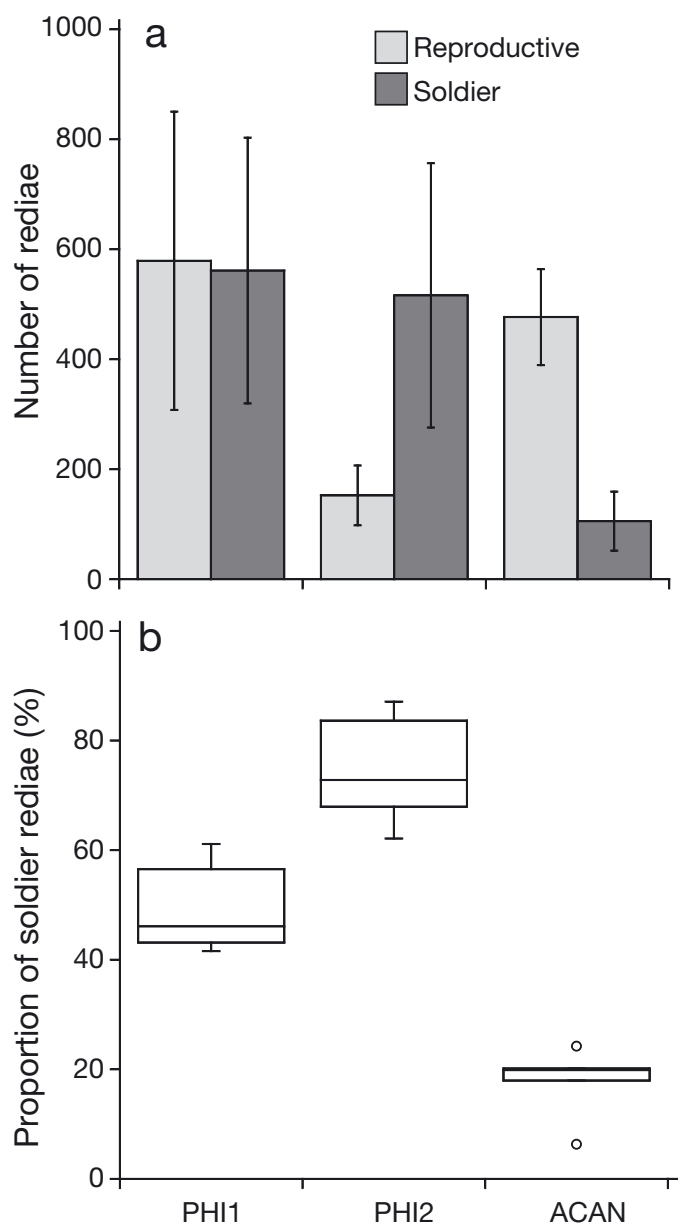

Fig. 6. (a) Number of reproductive and solider rediae in single colonies. Philophthalmid sp. I (PHI1), Philophthalmid sp. II (PHI2) and Acanthoparyphium sp. I (ACAN). Means \pm SD. (b) Proportion of soldier rediae in single colony of PHI1, PHI2 and ACAN. The boxplots depict median (line), interquartile range (box), general data range (whiskers), and outliers (O)

\section{DISCUSSION}

All 3 trematode species examined have 2 morphologically distinct redia morphs with different functions (either reproductives or soldiers; Fig. 1). These findings are consistent with those by Hechinger et al. (2011) who demonstrated such social organization involving soldier and reproductive castes for Himasthla sp. B in Cerithideopsis californica. Reproductives are large and filled with larval cercariae, while soldiers are small and do not contain free embryos or cercariae. Soldiers are more common than reproductives outside of the host gonadal region, presumably at sites where new infections occur. Finally, only soldiers attacked heterospecifics, suggesting soldiers play a significant role in protecting their colony from heterospecific competitors.
Consistent with other social systems such as ants, termites, a sea anemone and snapping shrimp (Ayre \& Grosberg 1996, Duffy 1996, Korb 2007, Peeters \& Molet 2010), reproductives are larger than soldiers. In the present study, reproductives were 10 to 160 times larger than soldiers (Figs. $2 \& 3$ ). These size differences are often related to their distinct roles in the colony. Particularly, since offspring production is correlated with body size (Honěk 1993), large body size can be one of the important traits for reproductives.

Most reproductives contained numerous cercaria embryos, while soldiers did not. It is possible that soldiers are immature rediae and will produce embryos later. If so, one would expect intermediate-sized morphs between soldiers and reproductives and the redia size distribution should be unimodal. However, small reproductives were infrequently observed in the present study (Fig. 2). Further, the size of soldiers and reproductives showed a bimodal distribution and did not overlap (Fig. 2b). This is consistent with the pattern observed in Himasthla sp. B colonies (Hechinger et al. 2011) and suggests they are different castes. Similarly, Leung \& Poulin (2011) measured all rediae in 2 colonies of Philophthalmus sp. and found that redia size was markedly bimodal between soldiers and reproductives. These results suggest that soldiers are not just immature reproductives but form a non-reproductive caste. Another possibility is that soldiers produce embryos in response to an appropriate stimulation. Such caste transformation has been demonstrated in a sea anemone (Ayre \& Grosberg 1995, 2005), wasps (Field \& Foster 1999) and a molerat (Henry et al. 2007). Further experimental study is needed to evaluate this possibility.

Soldiers in social organisms often develop body parts used for aggressive behavior. For example, soldiers in ants and termites have larger heads (Detrain \& Pasteels 1992, Scheffrahn \& Su 1994, Passera et al. 1996), and those in the sea anemone have more fighting tentacles (Ayre \& Grosberg 1996). The trematode soldiers also exhibited morphological specializations for defense. Although soldiers are small, they have large mouthparts relative to their body size (Fig. 4b). This should enhance their ability to defend against new infections which would compete for host resources (Lie 1973, Hechinger et al. 2011).

Soldiers frequently attacked heterospecific rediae but never attacked rediae from the same colony (Fig. 5). Additionally, soldiers never attacked conspecific rediae in Philophthalmid sp. II and Acanthoparyphium sp. I. Although soldiers attacked conspecific rediae in Philophthalmid sp. I, it occurred only once and was not statistically significant (Fig. 5). My 

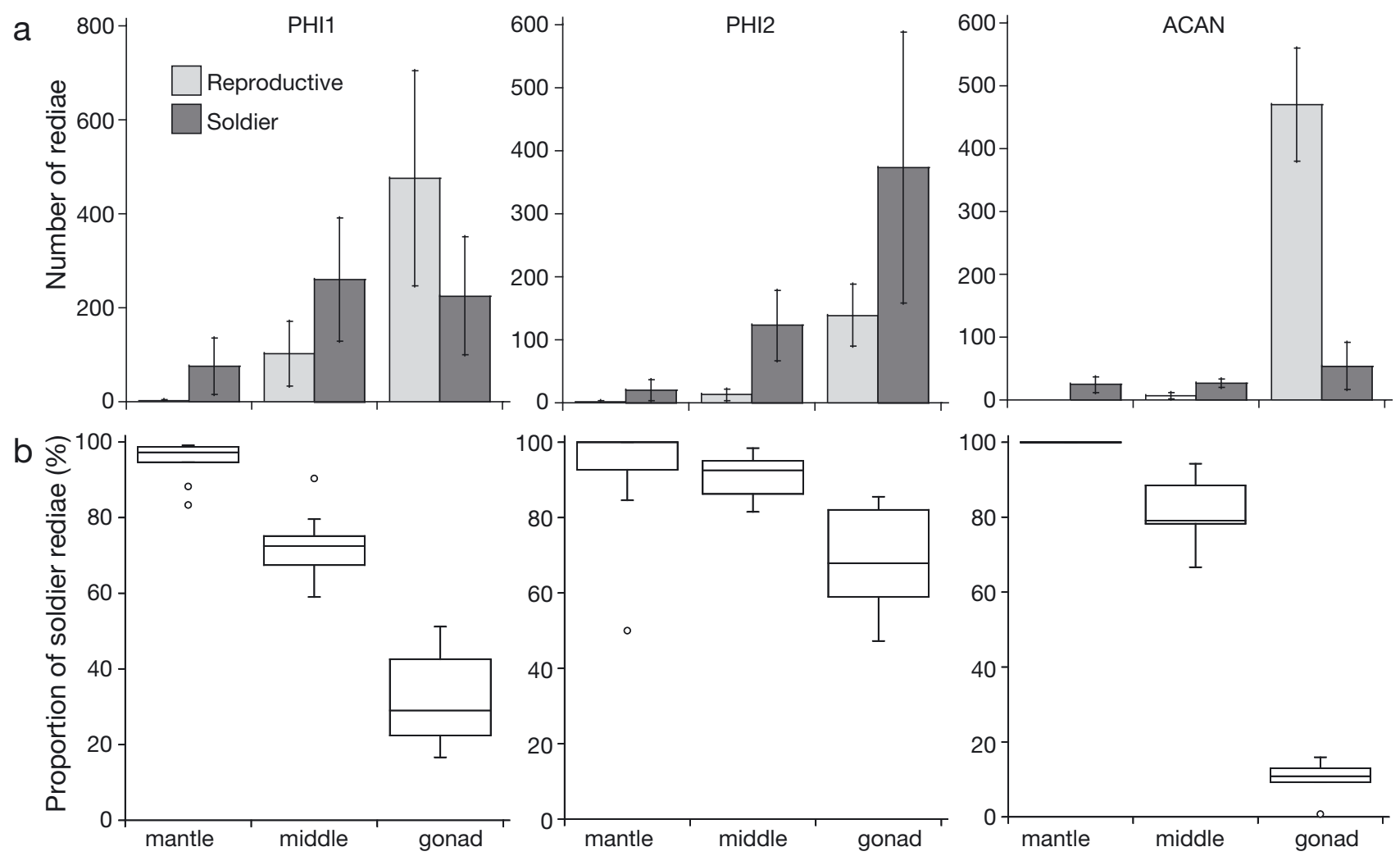

Fig. 7. (a) Number of reproductive and soldier rediae in the mantle, middle, and gonad regions. Philophthalmid sp. I (PHI1), Philophthalmid sp. II (PHI2) and Acanthoparyphium sp. I (ACAN). Means \pm SD. (b) Proportion of soldier rediae in single colony of PHI1, PHI2 and ACAN. Boxplots as in Fig. 6

findings suggest that soldiers can recognize heterospecifics, but cannot distinguish conspecific colonies. This is contrary to the intraspecific-colony recognition demonstrated in Himasthla sp. B (Hechinger et al. 2011), and shows that there are variations in conspecific competitor recognition among trematode species. Non-colony recognition is also observed in other social organisms such as thrips (Crespi 1992) and aphids (Foster 1990, Aoki et al. 1991).

While soldiers repeatedly contacted the body surface of their colony mates using their mouths, they never attacked them. This movement and contact may be a form of redial recognition, potentially via a chemosensory response. Some ants use chemical agents to identify colony members (Ozaki et al. 2005), and, similarly, trematode soldiers may use agents released from rediae to distinguish colony mates from heterospecifics. Indeed, trematode rediae secrete numerous secretory-excretory products (Iakovleva et al. 2006). While these substances have been considered to play a role in snail host-trematode interactions (reviewed in Loker 2010), they may also contribute to trematode-trematode recognition. Further research is needed to evaluate this hypothesis.
There can be costs and benefits to increasing the number of soldiers in the colony. The colony may be greatly protected if there are abundant soldiers, but there could be an energetic cost to the production of soldiers. Therefore, there may be a trade-off between production and defense at the colony level. There are large variations in the numbers of soldiers among the 3 species (Fig. 6a). The ratio of soldiers relative to reproductives was highest in Philophthalmid sp. II and lowest in Acanthoparyphium sp. I (Fig. 6b). Philophthalmid sp. II appears to adopt a strategy that invests in higher levels of defense and they protect their colony for a long time to increase lifetime production. In contrast, Acanthoparyphium sp. I may cut the cost of defense to permit greater levels of reproduction before other trematodes invade its colony. In addition to species-specific strategies, environmental factors like competition and resources should also affect the soldier ratio, since selection should favor a high soldier ratio when the invasion risk is high (Harvey et al. 2000). Since trematode diversity and prevalence (which are associated with invasion risk) greatly vary among local sampling sites in Batillaria attramentaria (Miura et al. 2005, Miura unpubl. 
data), these snails and trematodes could provide an ideal system to study the evolution of the soldier caste ratio in relation to environmental factors.

Most reproductives were distributed in the gonadal tissue of snails, while soldiers were distributed more widely throughout the snail body (Fig. 7a) and showed the highest relative proportion in mantle tissue (Fig. 7b). As Hechinger et al. (2011) suggested, soldiers in the mantle region of the snail body appear to be important for protection because more miracidia invade here (Galaktionov \& Dobrovolskij 2003). It would obviously be advantageous to eliminate invaders quickly, before they produce numerous clones. The distribution pattern of soldiers in the snail body likely reflects the invading strategy of competitors and the countermeasures of soldiers.

There are 3 cryptic species reported in Philophthalmid sp. II (Miura et al. 2005). They are currently morphologically indistinguishable, but genetically distinct. Therefore, the Philophthalmid sp. II colonies analyzed in the present study may include cryptic species. Further genetic study may reveal species-specific differences in the division of labor among the cryptic species. However, in all cases, every individual colony analyzed in the present study possessed soldiers.

The social organization in trematodes is closely parallel to that in some terrestrial insects. For example, some aphids have soldiers to defend their colonies against predators. As with the trematode soldiers, the aphid soldiers do not reproduce and are small but aggressive (Aoki 1977). Further, they are not able to distinguish conspecific colonies (Foster 1990, Aoki et al. 1991). Similar caste formation is observed in the larval stage of polyembryonic parasitoid wasps. Soldiers of the wasps are slightly smaller than reproductives, but aggressive, and defend their colonies (and host resources) against conspecific and heterospecific competitors (Harvey et al. 2000, Giron et al. 2004). In trematodes, aphids and parasitoid wasps, soldiers are clone mates of reproductives and thus there are no genetic conflicts between the 2 caste groups. Despite the taxonomic, morphological and ecological heterogeneity of the above named taxa, there are several similarities in their social systems. Further comparison of their social systems may help to illuminate important traits concerning the evolution of sociality.

Hechinger et al. (2011) suggested that a division of labor is probably widespread among trematodes. I found that 3 trematodes infecting the Asian mud snail Batillaria attramentaria also exhibited a similar social organization to that found in Himasthla sp. B in
North America (Hechinger et al. 2011). Similarly, Leung \& Poulin (2011) also reported the presence of solders and reproductives in Philophthalmus sp. from the New Zealand mud snail Zeacumantus subcarinatus, but their behavior differences and their distributions within the host were not evaluated. Combined, these studies indicate that the social organization involving reproductive and non-reproductive soldier castes in trematodes is geographically widespread, occurring in North America, East Asia and Oceania. Trematodes infecting molluscan hosts are common and diverse and are relatively well studied organisms. Yet, the discovery of sociality in trematodes has been very recent (Hechinger et al. 2011), suggesting that this phenomenon is underappreciated and quite common. However, to date, all the reported trematode species with soldiers belong to 2 closely related families (the Echinostomatidae [Himasthla sp. B, Acanthoparyphium sp. I] or the Philophthalmidae [Philophthalmid sp. I, Philophthalmid sp. II and Philophthalmus sp.]) (Olson et al. 2003). This may be because the social organization in trematodes evolved only in a small group, or because sampling is limited. Further research on a taxonomically broad range of trematode species will elucidate this and offer opportunities to test hypotheses on the evolutionary origin of caste formation.

Acknowledgements. I thank K. Kimura, T. Hirano and M. Miura for their field assistance, and N. Sato for her laboratory assistance. I am especially indebted to R. Hechinger for his invaluable logistical assistance and for providing useful comments on the manuscript. Three anonymous reviewers provided useful comments. Support was provided by Japan Promotion of Science (Grant-in-Aid for Research Activity Start-up) and Program to Disseminate Tenure Tracking System of the Ministry of Education, Culture, Sports, Science and Technology, the Japanese Government.

\section{LITERATURE CITED}

Aoki S (1977) Colophina clematis (Homoptera, Pemphigidae), an aphid species with 'soldiers'. Kontyu 45:276-282 (in Japanese)

Aoki S, Kurosu U, Stern DL (1991) Aphid soldiers discriminate between soldiers and non-soldiers, rather than between kin and non-kin, in Ceratoglyphina bambusae. Anim Behav 42:865-866

Ayre D (1982) Inter-genotype aggression in the solitary sea anemone Actinia tenebrosa. Mar Biol 68:199-205

Ayre DJ, Grosberg RK (1995) Aggression, habituation, and clonal coexistence in the sea anemone Anthopleura elegantissima. Am Nat 146:427-453

Ayre D, Grosberg R (1996) Effects of social organization on inter-clonal dominance relationships in the sea anemone Anthopleura elegantissima. Anim Behav 51:1233-1245 
Ayre DJ, Grosberg RK (2005) Behind anemone lines: factors affecting division of labour in the social cnidarian Anthopleura elegantissima. Anim Behav 70:97-110

Batra SWT (1964) Behavior of the social bee, Lasioglossum zephyrum, within the nest (Hymenoptera: Halictidae). Insectes Soc 11:159-185

Cable RM (1971) Parthenogenesis in parasitic helminths. Am Zool 11:267-272

> Chapman RE, Bourke AFG (2001) The influence of sociality on the conservation biology of social insects. Ecol Lett 4: 650-662

Crespi BJ (1992) Eusociality in Australian gall thrips. Nature 359:724-726

Detrain C, Pasteels JM (1992) Caste polyethism and collective defense in the ant, Pheidole pallidula: the outcome of quantitative differences in recruitment. Behav Ecol Sociobiol 29:405-412

Duffy JE (1996) Eusociality in a coral-reef shrimp. Nature 381:512-514

> Field J, Foster W (1999) Helping behaviour in facultatively eusocial hover wasps: an experimental test of the subfertility hypothesis. Anim Behav 57:633-636

> Foster W (1990) Experimental evidence for effective and altruistic colony defence against natural predators by soldiers of the gall-forming aphid Pemphigus spyrothecae (Hemiptera: Pemphigidae). Behav Ecol Sociobiol 27: 421-430

Galaktionov KV, Dobrovolskij AA (2003) The biology and evolution of trematodes: an essay on the biology, morphology, life cycles, transmission, and evolution of digenetic trematodes. Kluwer Academic Publishers, Dordrecht

> Giron D, Dunn DW, Hardy ICW, Strand MR (2004) Aggression by polyembryonic wasp soldiers correlates with kinship but not resource competition. Nature 430:676-679

> Harvey JA, Corley LS, Strand MR (2000) Competition induces adaptive shifts in caste ratios of a polyembryonic wasp. Nature 406:183-186

Hechinger RF (2007) Annotated key to the trematode species infecting Batillaria attramentaria (Prosobranchia: Batillariidae) as first intermediate host. Parasitol Int 56: 287-296

Hechinger RF, Lafferty KD, Mancini FT, Warner RR, Kuris AM (2009) How large is the hand in the puppet? Ecological and evolutionary factors affecting body mass of 15 trematode parasitic castrators in their snail host. Evol Ecol 23:651-667

> Hechinger RF, Wood AC, Kuris AM (2011) Social organization in a flatworm: trematode parasites form soldier and reproductive castes. Proc $\mathrm{R}$ Soc Lond B 278:656-665

Henry EC, Dengler-Crish CM, Catania KC (2007) Growing out of a caste-reproduction and the making of the queen mole-rat. J Exp Biol 210:261-268

Honěk A (1993) Intraspecific variation in body size and fecundity in insects: a general relationship. Oikos 66: 483-492

Iakovleva NV, Shaposhnikova TG, Gorbushin AM (2006) Rediae of echinostomatid and heterophyid trematodes suppress phagocytosis of haemocytes in Littorina littorea

Editorial responsibility: Steven Morgan,

Bodega Bay, California, USA
(Gastropoda: Prosobranchia). Exp Parasitol 113:24-29

Klahn JE, Gamboa GJ (1983) Social wasps: discrimination between kin and nonkin brood. Science 221:482-484

Korb J (2007) Termites. Curr Biol 17:R995-R999

Kuris AM, Hechinger RF, Shaw JC, Whitney KL and others (2008) Ecosystem energetic implications of parasite and free-living biomass in three estuaries. Nature 454: 515-518

Leung TLF, Poulin R (2011) Small worms, big appetites: ratios of different functional morphs in relation to interspecific competition in trematode parasites. Int J Parasitol 41:1063-1068

Lie KJ (1973) Larval trematode antagonism: principles and possible application as a control method. Exp Parasitol 33:343-349

Loker ES (2010) Gastropod immunobiology. Adv Exp Med Biol 708:17-43

Matthews RW (1968) Microstigmus comes: sociality in a sphecid wasp. Science 160:787-788

May RM (1989) An inordinate fondness for ants. Nature 341: 386-387

- Michener CD (1969) Comparative social behavior of bees. Annu Rev Entomol 14:299-342

Miura O, Kuris AM, Torchin ME, Hechinger RF, Dunham EJ, Chiba S (2005) Molecular-genetic analyses reveal cryptic species of trematodes in the intertidal gastropod, Batillaria cumingi (Crosse). Int J Parasitol 35:793-801

Myles TG (1999) Review of secondary reproduction in termites (Insecta: Isoptera) with comments on its role in termite ecology and social evolution. Sociobiology 33:1-94

Olson PD, Cribb T, Tkach V, Bray R, Littlewood D (2003) Phylogeny and classification of the Digenea (Platyhelminthes: Trematoda). Int J Parasitol 33:733-755

Ozaki M, Wada-Katsumata A, Fujikawa K, Iwasaki M and others (2005) Ant nestmate and non-nestmate discrimination by a chemosensory sensillum. Science 309: 311-314

> Passera L, Roncin E, Kaufmann B, Keller L (1996) Increased soldier production in ant colonies exposed to intraspecific competition. Nature 379:630-631

> Peeters C, Molet M (2010) Evolution of advanced social traits in phylogenetically basal ants: striking worker polymorphism and large queens in Amblyopone australis. Insectes Soc 57:177-183

> Rhoden P, Foster W (2002) Soldier behaviour and division of labour in the aphid genus Pemphigus (Hemiptera, Aphididae). Insectes Soc 49:257-263

Scheffrahn RH, Su NY (1994) Keys to soldier and winged adult termites (Isoptera) of Florida. Fla Entomol 77: $460-474$

Wilson EO (1971) The insect societies. Harvard University Press, Cambridge, MA

Wilson EO, Kinne O (1990) Success and dominance in ecosystems: the case of the social insects. Ecology Institute, Oldendorf/Luhe

Yamaguti S (1975) A synoptical review of life histories of digenetic trematodes of vertebrates with special reference to the morphology of their larval forms. Keigaku Publishing Company, Tokyo

Submitted: February 17, 2012; Accepted: June 15, 2012

Proofs received from author(s): September 24, 2012 